\title{
Research
}

\section{Why Forests Are Important for Global Poverty Alleviation: a Spatial Explanation}

\author{
William D. Sunderlin $^{1,2}$, Sonya Dewi ${ }^{3}$, Atie Puntodewo ${ }^{2}$, Daniel Müller ${ }^{4,5}$, Arild Angelsen ${ }^{2,6}$, and \\ Michael Epprecht ${ }^{7}$
}

\begin{abstract}
Forests have been declared important for the well-being of the poor because of the kinds of goods and services that they provide. We asked whether forests are important for the poor not only because of the kinds of goods and services they provide, but also because they tend to be located where the poor are. We conducted a spatial analysis to ascertain the degree of spatial association between poverty and forests in seven countries: Brazil, Honduras, Malawi, Mozambique, Uganda, Indonesia, and Vietnam. For most of these countries, there was a significant positive correlation between high natural forest cover and high poverty rate (the percentage of the population that is poor) and between high forest cover and low poverty density (the number of poor per unit area). We explain the findings and discuss policy implications and topics for future research.
\end{abstract}

Key Words: deforestation; forest; poverty; spatial analysis

\section{INTRODUCTION}

The poor are said to rely on forests to maintain their well-being (Byron and Arnold 1999, Angelsen and Wunder 2003, Vedeld et al. 2004) and in some cases as a source of income improvement (e.g., RuízPérez et al. 2004). Forests provide a "subsidy from nature" of free environmental goods and services (Anderson et al. 1991). These goods and services include a wide diversity of products for home consumption and sale, new agricultural lands, restoration of soil fertility on fallow lands used in swidden cultivation cycles, and access to fresh water through the watershed function of forests (Sunderlin et al. 2005). Forests can fulfill various roles in the livelihoods of the rural poor. They provide a source of regular subsistence for people who live in and near forests in the form of food, fuel, forage, building materials, and medicines, among other products (Byron and Arnold 1999). The diversification of income sources is important to the rural poor as a means to minimize risk exposure (Ellis 2000). Forest resources provide a source of gap-filler income in between agriculture harvests and serve as a safety net in the event of private calamity such as a death in the family or community calamity such as failed harvest, famine, flood, hurricane, or war (Angelsen and Wunder 2003, Takasaki et al. 2004). Forests can function as a form of savings (Chambers et al. 1993) and as a form of natural insurance (Pattanayak and Sills 2001, McSweeney 2004). The open-access character of wide areas of public forests in developing countries assure that the poor are often relatively unhindered in making use of forest resources (Sunderlin et al. 2005). All of these documented benefits share a trait in common: They all concern what forests are to poor people.

Here, we ask whether forests are critical for supporting the well-being of the poor, not just because of what they are, but also because of where they are. Stated differently, we ask if the pro-poor characteristics of forests are meaningful because the poor and forests tend to share the same space.

What kind of evidence is there that the poor and forests occupy the same space? Various countrylevel observations have been made of the tendency of the rural poor to be located in or nearby forests.

\footnotetext{
${ }^{1}$ Rights and Resources Group, ${ }^{2}$ Center for International Forestry Research, ${ }^{3}$ World Agroforestry Centre, ${ }^{4}$ Leibniz Institute of Agricultural Development in Central and Eastern Europe (IAMO), ${ }^{5}$ Humboldt-Universität zu Berlin, ${ }^{6}$ Norwegian University of Life Sciences, ${ }^{7}$ Swiss National Center of Competence in Research (NCCR) "North-South", University of Berne
} 
In China, there is an observed overlap between counties categorized as severely poor and counties with abundant forest resources (Zhou and Veeck 1999). In India, Poffenberger et al. (1996, as cited in Khare et al. 2000) found that there is a strong association between the location of tribal people, who tend to be among the poorest people, and the location of forests. Approximately 275 million people in India's rural areas depend on forests for a portion of their income; forest dwellers, who are disproportionately tribal, are among the poorest and most vulnerable people in India (World Bank 2006). Approximately half of India's 350 million poor people are concentrated in three states in which natural, physical, social, and human capital are low and the greatest poverty is experienced by people in forest-based economies; $84 \%$ of India's tribal ethnic minorities live in forested areas (Mehta and Shah 2003). Shah and Guru (2004:8) explain that the "incidence of poverty, reflected by head count ratio, is higher than the all-India estimates for the majority of forest based states. Compared to this, the incidence of poverty is substantially lower among dryland states except Maharashtra. The pattern is more or less the same during 1993-1994 and 1999-2000."

Five pieces of recent research deepen the understanding of the spatial coincidence of poverty and forests by quantifying the patterns, distinguishing poverty by type (i.e., rate and density), and discussing the factor of distance from urban areas. The poverty rate is the proportion of people who are poor in a given area; the poverty density is the absolute number of poor per unit area (individuals $/ \mathrm{km}^{2}$ ) in a given area. In a case study of Nicaragua, Chomitz (K. C. Chomitz unpublished manuscript) found that "remoteness from towns and markets is associated with high poverty rates, high forest cover, and low population density." Similarly, in a case study of Vietnam, Müller et al. (2006) demonstrated, through bivariate local indicators of spatial association analysis, a strong statistical correlation among the location of low poverty density, high poverty rate and severity, and high forest cover in remote areas where ethnic minorities tend to be dominant. Conversely, they found high correlation among areas of high poverty density, low poverty rate, and low forest cover in urban and peri-urban areas and in the Mekong and Red River deltas. Dasgupta et al. (2005) found that poverty density in Cambodia tends to be high in areas of low forest cover and low in areas of high forest cover. Drawing on Sunderlin et al.'s (2007) case study work, Chomitz (2007) strengthens the case that remoteness and forests are positively related to poverty rate and inversely related to poverty density.

We addressed the following questions. Is there a clear association between poverty and forests in developing countries on three continents? If so, what are the characteristics of that association? To answer these questions, we conducted spatial analysis of seven country cases: Brazil, Honduras, Malawi, Mozambique, Uganda, Indonesia, and Vietnam. We then discuss the policy implications of the findings, giving attention to the way the findings can be implemented in national poverty reduction strategies. These are important objectives because forest resources are often given little, if any, attention in national strategies for poverty reduction (e.g., Oksanen and Mersmann 2003).

\section{METHODS}

\section{Criteria for the selection of the seven case studies}

Initially, we sought to analyze as many developing country cases as possible that covered the largest possible number of people living in and near forests and the largest area of forests. In this way, our sample would be broadly representative of forests of developing countries as a whole. We sought country cases that met the following minimum requirements: the forest cover was non-negligible; relatively recent and reliable population and poverty data were available at a relatively fine level of disaggregation; and the population and poverty data were specified at the level of the district and could be attributed to a geo-referenced district map.

In seeking country cases that met these minimum data requirements, we learned that there were very few such countries. Because of unavailable data or data that did not meet our specifications, it was not possible to include certain countries that we would have liked to include such as the important forest countries of Mexico, Cameroon, Democratic Republic of Congo, and Papua New Guinea and countries that had large populations such as China and India. However, based on our criteria, we chose for analysis seven countries from three continents: Brazil, Honduras, Malawi, Mozambique, Uganda, Indonesia, and Vietnam. 


\section{Poverty and population data}

The poverty and population data were based largely on official national censuses and survey data. Four of the seven data sets (Malawi, Mozambique, Uganda, and Vietnam) were based on small area estimates (Benson 2002, Minot et al. 2003, International Livestock Research Institute 2005, Simler et al. 2005). This approach involves indirect estimation procedures that combine the spatial precision of census data with the substantive depth of surveys. Some of the data sets were assembled by national institutions (Badan Pusat Statistik 2000, Robles 2003; Instituto de Pesquisa Econômica Aplicada national poverty data for the year 2000: http://ipeadata.gov.br/), and others were created by national government institutions collaborating with international research organizations (e.g., the International Food Policy Research Institute in Malawi and Vietnam and the International Livestock Research Institute in Uganda). In all cases, the numbers of poor were determined by identifying households that were below a countryspecific poverty line. There is a wide diversity of approaches in determining poverty lines in these various countries.

\section{Forest cover data}

Forest cover data were obtained from the Continuous Fields $1 \mathrm{~km}$ Tree Cover map produced by DeFries et al. $(2000 a, b)$ from Advanced Very High Resolution Radiometer (AVHRR) images for the period of 1992-1993. This map provides estimates of forest canopy density as a percentage of area within $1-\mathrm{km}^{2}$ cells. Following the Food and Agriculture Organization's (2001) model of forest cover classification, we produced a new map according to the following range of values: $0-10 \%$ tree crown cover $=$ nonforest $; 10-40 \%=$ open forest; and $40-100 \%=$ closed forest. The coarse-resolution Tree Cover map was used despite some limitations because it provides forest cover data for all of the country cases and because the uniformity of the data collection method and of the forest class definitions allows a degree of comparability among the countries studied.

\section{Pearson correlation, Moran's I, and local indicators of spatial association}

We used Pearson correlation to see if there were any general, national patterns of relationships between poverty and forests. This approach addressed spatial variation, but not spatial dependence. Thus, we used Moran's $I$ to measure spatial autocorrelation and identify spatial clusters in the data. The univariate global Moran's I measures the linear association of a variable with itself in space and was used to test the strength of global spatial autocorrelation of poverty and of forest. Moran's I ranges between -1 and +1 . A positive Moran's $I$ indicates spatial clustering of either high or low values, whereas a Moran's I near zero implies no spatial autocorrelation, or spatial randomness. A checkerboard pattern of dissimilar values results in a Moran's I close to -1 . Moran's $I$ is weighted by a matrix that reflects the spatial proximity used to define the neighborhood (Anselin 1988).

We explored the relationships between poverty and forest at the national level taking into account spatial dependence using bivariate global Moran's $I$. Further, local Moran's I, also called local indicators of spatial association (LISA) analysis, was conducted to identify regions within a country where there were different patterns of relationships between poverty and forest.

The bivariate local spatial autocorrelation measure using Moran's I statistic, derived from Anselin's formula (1995), is written as:

$$
I_{l}=z_{x i} \sum_{j=1, j \neq i}^{N} w_{i j} z_{y j}
$$

where $x$ and $y$ are the poverty and forest variables for district $i$ and the neighboring district $j$, respectively; and $z_{x}$ and $z_{y}$ are the standardized $z-$ scores of variables $x$ and $y$, respectively. The spatial weight matrix $w_{i j}$ can be defined as a binary contiguity matrix that provides the spatial structure for the locations that are included in the calculation of the local Moran's I. In the case of first-order contiguity weights, all observations that share a common border have $w_{i j}=1$, otherwise $w_{i j}=0$. A 
first-order queen contiguity matrix defined the spatial extent of the observations that we used. The queen criterion considers all surrounding neighbors (districts) that have a common border or common vertices with the observation of interest. The matrix choice is based on logical insights and therefore involves an arbitrary component. The diagonal elements in the matrix are zero and the off-diagonal elements represent the specified neighborhood around observation $i$. The average of all local Moran's $I$ indices over all observations (districts) $N$ is proportional to the global Moran's I (Anselin 1995).

In other words, Eq. 1 indicates spatial clusters of high (or low) values of one variable $x$ surrounded by high (or low) values of another variable $y$. High and low values in this context are defined as values that are greater than and less than the mean of the respective variable, respectively. This provides a measure for the spatial association between two variables in a neighborhood that is defined by the spatial weights matrix.

All LISA indicators were calculated using GeoDa ${ }^{\mathrm{TM}}$ (Anselin 2005). To create the maps, a randomization approach of 999 permutations was used to avoid large sensitivities in the results. The randomization assumes the location of the values and their spatial arrangement to be irrelevant. Based on the randomization, different theoretical standard deviations for Moran's I are obtained, each yielding a different $p$-value as a pseudo-significance. The threshold value of $p=0.05$ defines significance. The $p$-values follow an asymptotically standard-normal distribution that allows the evaluation of their significance level by comparing them to a reference distribution (Anselin 1995).

\section{Application of local indicators of spatial association}

We sought to understand how varying magnitudes of poverty (i.e., low or high poverty rate or density) are related spatially to varying proportions of forest cover (i.e., low or high) at the level of the district within the seven case study countries. Again, the poverty rate is the proportion of people who are poor in a given area, and the poverty density is the absolute number of poor people in a given area. Forest cover is the proportion of closed forest (40$100 \%$ canopy cover) per unit district area.
Measures of poverty and forest cover each have the potential for spatial autocorrelation. For example, univariate Moran's I calculations suggested that similar percentages of forest cover tend to be clustered in area units that are close to one another. In applying the bivariate global Moran's I statistic to the case study data, autocorrelations of poverty and forest data were discerned at the country level. In applying the bivariate LISA method, spatial clusters were produced that visualized the relationships between two variables: the correlation of poverty rate and forest cover in the surrounding area; and the correlation of poverty density and forest cover in the surrounding area.

The boundaries between high $(\mathrm{H})$ and low (L) poverty rate and between high $(\mathrm{H})$ and low $(\mathrm{L})$ poverty density are determined by the LISA analysis in each country calculation. So, for example, for districts in which correlations of forest cover and poverty rate are significant, the LISA cluster maps display significant correlations using the following labels: HIGH-HIGH $(\mathrm{HH})=$ high forest cover and high poverty rate; LOW-LOW (LL) = low forest cover and low poverty rate; HIGH-LOW (HL) = high forest cover and low poverty rate; LOW-HIGH $(\mathrm{LH})=$ low forest cover and high poverty rate.

In the LISA analysis, the categorization into these four groups was conducted based on three criteria. For example, for district $i$ to be classified as HL, the following three conditions must hold: the bivariate local Moran's $I_{i}$ is significantly different from zero and negative, or, if it is $\mathrm{HH}$ or LL, then it is significantly different from zero and positive; the forest cover of district $i$ is greater than the national mean forest cover; and the mean poverty of the districts neighboring district $i$ is less than the national mean poverty. These rules apply similarly whether the poverty measure is rate or density.

Each of the figures that displays the findings shows four maps: forest cover and major urban areas; population density; LISA analysis of forest cover and poverty rate; and LISA analysis of forest cover and poverty density. The juxtaposition of the maps showing urban areas and population density (maps 1 and 2) with the maps showing the LISA results (maps 3 and 4) is important because it helps to show, albeit only visually, the relationship between remoteness, defined simply as distance from urban centers, and the patterns of association between poverty and forests as indicated by the LISA analysis. 


\section{Strengths and weaknesses of the approach}

The main justifications for measuring and testing global and local spatial autocorrelation in studying the relationship between poverty and forest cover are as follows. The global Moran's I technique allows the evaluation of the hypothesis that spatial autocorrelation is important in assessing the country-level relationship between poverty and forests. We assume not only that positive spatial autocorrelation will be discernible in each univariate case of poverty and forest cover (i.e., that both poverty and forest cover are spatially clustered in some places), but also that there is spatial variation in the relationship between forest cover and poverty. The LISA method provides an efficient way to detect and visualize correlations at the local level that are not readily discernible when pooling data at the national level.

Although we think the methods we used are appropriate to our objectives, there are important drawbacks and limitations that should be considered. First, the examination of just two variables, i.e., poverty and forest, runs the risk of producing oversimplified and perhaps even misleading conclusions about their relationship to one another. There are numerous variables that can affect the relationship between poverty and forest cover, among them: the degree of remoteness from urban areas; the presence or absence of roads and markets; topography; and soil quality. Nevertheless, it is useful to measure the strength of the association between poverty and forests to test and verify anecdotal information about their spatial relationship and to set the stage for studies that use a multivariate approach. We chose to avoid multivariate analyses at this stage because we wanted to know to what extent the use of just two variables could explain the largely anecdotal analysis of the poverty-forest spatial link to date. Moreover, it would have been challenging to conduct multivariate analyses because of the lack of data layers that could be applied across all case countries.

Second, because of the lack of time series data on poverty and forest cover, we restricted ourselves to a static measure of the relationship between the two variables. This restricts our ability to draw definitive conclusions about cause and effect patterns between the two, and also restricts us to educated guesses about where the relationship is heading over time.

Third, AVHRR data are coarse, risking inaccuracy in capturing vegetation reflectance. Depending on the landscape patterns, the under- and overestimation of vegetation density can be significant. This can be especially problematic in areas of the case countries that have ample forest-savannah transition zones or highly fragmented mosaic-type landscapes.

Fourth, there is a temporal gap between the AVHRR data (1992-1993) and the socioeconomic data (oldest 1998, newest 2001). In some countries such as Indonesia, there has been net deforestation during this temporal gap, whereas in others such as Vietnam, net forest cover has either been stable or has increased slightly.

The fifth problem concerns the arbitrariness of the cut-off points in defining forest as closed forest, that is, 40-100\% crown cover, as per the Food and Agriculture Organization's (2001) system of classification. Our definition excludes two types of land cover that are of potential relevance. First, this narrow definition of forest excludes open forest (10-40\% crown cover). Thus, in dry and subtropical countries (e.g., the Miombo woodlands countries such as Angola, Burundi, Democratic Republic of Congo, Malawi, Mozambique, Tanzania, Zambia, and southern Zimbabwe), large areas of sparse woodlands that can be properly called forests and upon which large segments of the population depend for their livelihoods will not be considered if the crown cover is $<40 \%$. Second, this narrow definition of forest omits from the forest category large areas of shrubs and other vegetative cover in the humid tropics that may not be considered as forests in the tropical context, although they may play similar roles to forests in local livelihoods. Our definition of forest more strongly equates with the core attributes of remoteness (i.e., distance from urban areas and roads, presence of indigenous people, lack of market access), making some of our observations about the link between remoteness, poverty rate, and forests stand out in bolder relief. We experimented with the approach of defining forest either narrowly or widely. In the end, we had to choose one definition or the other to avoid the awkwardness of applying different definitions of forest across the seven case countries and concluded that the benefits of the narrow definition outweighed the disadvantages.

Finally, we must acknowledge that the comparisons and contrasts among the case countries are crude. Although the use of AVHRR data helps to standardize forest cover measures among countries, the shortcomings of AVHRR data tend to weaken the basis for comparison. The basis for comparison 
is also weakened by the fact that methods for measuring poverty differ among the countries. Nevertheless, if one assumes that all countries use broadly similar assumptions about what constitutes adequate or inadequate human well-being, the comparisons are at least minimally legitimate and useful.

\section{RESULTS}

\section{Pearson correlation and Moran's I}

The Pearson correlations and Moran's I suggest an ambiguous relationship between poverty and forests. The Pearson correlations and bivariate Moran's $I$ indicate that district-level correlations between poverty rate and forest cover were low at the national level, with small correlation coefficients for most cases, even though they were significant at $p \leq 0.05$ in five cases (Table 1 ). In these calculations, the Brazil and Uganda cases show an unexpected negative correlation. In the case of Brazil, this is because the districts classified as high poverty-low forest cover (HL) and low poverty-high forest cover (LH; 1772 districts) outnumber the districts classified as $\mathrm{HH}$ and LL (1280 districts); however, the HH and LL districts compose a much larger area than do the HL and LH districts. The poverty rate global Moran's I shows medium to strong correlation and significance at $p$ $=0.01$ for all countries. The forest cover global Moran's $I$ shows medium to strong correlation for all case countries, and significance at $p \leq 0.05$ for all seven countries.

\section{Maps of local indicators of spatial association}

By and large, the maps of local indicators of spatial association (LISA) tended to confirm earlier case studies that demonstrated a spatial association between poverty and forests (Figs. 1-7). However, some of the seven case countries conformed to this pattern, whereas others did not. The pattern is discerned visually by comparing the area of high forest cover to poverty rate and poverty density.

In most of the seven case countries, there was a broad tendency for high forest cover to be associated with high poverty rate, indicated by red shading in the forest vs. poverty rate map (Figs. 1-7). This area of red shading tends to conform to the area of closed forest in the forest and major urban areas map. This association is particularly strong in the case of Brazil and Vietnam; evident, but weaker in the case of Malawi, Mozambique, and Indonesia; and not evident in the case of Honduras and Uganda. We note, however, that one reason why the effect appears particularly strong in Brazil is because the forested districts are quite large and therefore tend to dominate the image.

There is also a broad tendency for high forest cover to be associated with low poverty density, indicated by pink shading in the forest vs. poverty density map (Figs. 1-7). This association is discernible for approximately three-quarters of the forest area in Brazil, Indonesia, and Vietnam; approximately half of the forest area in Honduras, Malawi, Mozambique; and only a small area of the forest in Uganda.

Given that large urban areas in developing countries will often have relatively little forest cover and that some are sometimes centers of economic dynamism, one can expect areas of low forest cover and low poverty rate in some cases. We see such areas, indicated by dark blue shading in the forest vs. poverty rate map (Figs. 1-7), in Brazil (Brasilia), Malawi (Lilongwe), Mozambique (Maputo), Indonesia (Jakarta), and Vietnam (Hanoi and Ho Chi Minh City). Most cities, however, either deviate from this pattern or show no significant association.

Our findings reveal the importance of remoteness: high population density tends to be centered in and around urban areas, and forest cover tends to be the mirror image of population density. Mozambique and Uganda are exceptions, with significant overlaps of high population density and high forest cover. Similarly, areas of high forest cover and high poverty rate and areas of high forest cover and low poverty density tend to be located away from big cities and in remote places.

\section{Overall findings}

We used the data from the forest vs. poverty rate map for each country (Figs. 1-7) and classified them according to the percentage area of closed forest (Fig. 8) and the percentage of the total number of poor people (Fig. 9) in each country. This allowed us to determine the relevance of the findings in terms of our key objects of concern: the area of closed forest and the number of poor people. 
Table 1. Pearson correlations and bivariate and univariate global Moran's I calculations for poverty rate and forest cover data from seven case study countries.

\begin{tabular}{lccccccc}
\hline \hline Country & No. districts & $\begin{array}{c}\text { Mean district } \\
\text { area }\left(\mathrm{km}^{2}\right)\end{array}$ & $\begin{array}{c}\text { SD of } \\
\text { district area } \\
\left(\mathrm{km}^{2}\right)\end{array}$ & $\begin{array}{c}\text { Pearson correl- } \\
\text { ation coefficient }\end{array}$ & $\begin{array}{c}\text { Bivariate g- } \\
\text { lobal Moran's } \\
I\end{array}$ & $\begin{array}{c}\text { Poverty rate } \\
\text { global Moran's } \\
I\end{array}$ & $\begin{array}{c}\text { Forest cover } \\
\text { global Moran's } \\
I\end{array}$ \\
\hline Brazil & 5507 & 1553.34 & 5746.82 & $-0.1139^{* *}$ & $-0.0983^{* *}$ & $0.4842^{* *}$ & $0.8554^{* *}$ \\
Honduras & 292 & 383.94 & 914.27 & $0.1250^{*}$ & 0.0588 & $0.4586^{* *}$ & $0.3902^{* *}$ \\
Indonesia & 351 & 5424.34 & 10652.99 & $0.2780^{* *}$ & $0.1268^{* *}$ & $0.5015^{* *}$ & $0.6609^{* *}$ \\
Malawi & 368 & 260.22 & 360.68 & $0.2142^{* *}$ & $0.0895^{* *}$ & $0.3658^{* *}$ & $0.3928^{* *}$ \\
Mozambique & 146 & 5359.85 & 4078.16 & 0.0428 & 0.0664 & $0.3510^{* *}$ & $0.4809^{* *}$ \\
Uganda & 34 & 1409.10 & 1013.26 & -0.3641 & $-0.2236^{*}$ & $0.4415^{* *}$ & $0.3093^{*}$ \\
Vietnam & 601 & 554.51 & 559.34 & $0.5710^{* *}$ & $0.4365^{* *}$ & $0.6843^{* *}$ & $0.7538^{* *}$ \\
\hline
\end{tabular}

$* p<0.05, * * p<0.01$.

In the case of Brazil and Vietnam, slightly $>70 \%$ of the districts that contained high forest cover also had a high rate of poverty (Fig. 8, dark red); the remainder of the districts with closed forest area $(<$ $30 \%$ ) comprised all other clusters. Conversely, Honduras showed only a small portion of closed forest area $(\sim 10 \%)$ in which high forest cover was associated with a high poverty rate; $\sim 40 \%$ of its closed forest is characterized by no statistical correlation between forest cover and poverty rate at the district level. Most case countries were between these two extremes. On average, $\sim 40 \%$ of the total closed forest area in the seven case countries was associated with a high poverty rate. On average, almost half of the forest area showed no significant relationship between high forest cover and poverty rate (Fig. 8, yellow).

Only a small percentage of the countries' poor people live in areas characterized with high forest cover and high poverty rate (Fig. 9, dark red). The range was from a low of $\sim 3 \%$ for Uganda and Indonesia to $\sim 20 \%$ for Vietnam. For all countries, with the exception of Mozambique, there were as many or more poor people in the low forest coverhigh poverty rate zone (Fig. 9, light blue) as there were in the high forest cover-high poverty rate zone (Fig. 9, dark red). For somewhat more than half of all poor, there is no significant relationship between poverty rate and forest cover (Fig. 9, yellow).

\section{Reasons for the coincidence of poverty and forests}

Why are many of the people who live in forested areas poor, and why do the rates of poverty in forested areas tend to be high? One reason is that poverty rates in developing countries tend to be higher in rural than in urban areas (Dercon 2008) and forests tend to be more abundant in rural than in urban areas. Does this mean that the supposed poverty-forest link is nothing more than a disguised poverty-rurality link? We think not. There is a spatial dimension that must be taken into account. Chronic poverty and poverty rates tend to be higher in remote rural areas, which are sometimes referred to as spatial poverty traps (Jalan and Ravallion 1997, Bird et al. 2002, Kanbur and Venables 2003), and forests, particularly primary forests, tend to be denser in remote rural areas. Why would forests, as a component of remote rural areas, tend to have high poverty rates? We see seven reasons:

1. Primordial low income in forested areas. Many centuries ago, standards of living were 
Fig. 1. Brazil. Maps of forest and major urban areas, population density, local indicators of spatial association (LISA) analysis of forest cover by poverty rate, and LISA analysis of forest cover by poverty density. District boundaries are not displayed to show the color patterns more clearly.
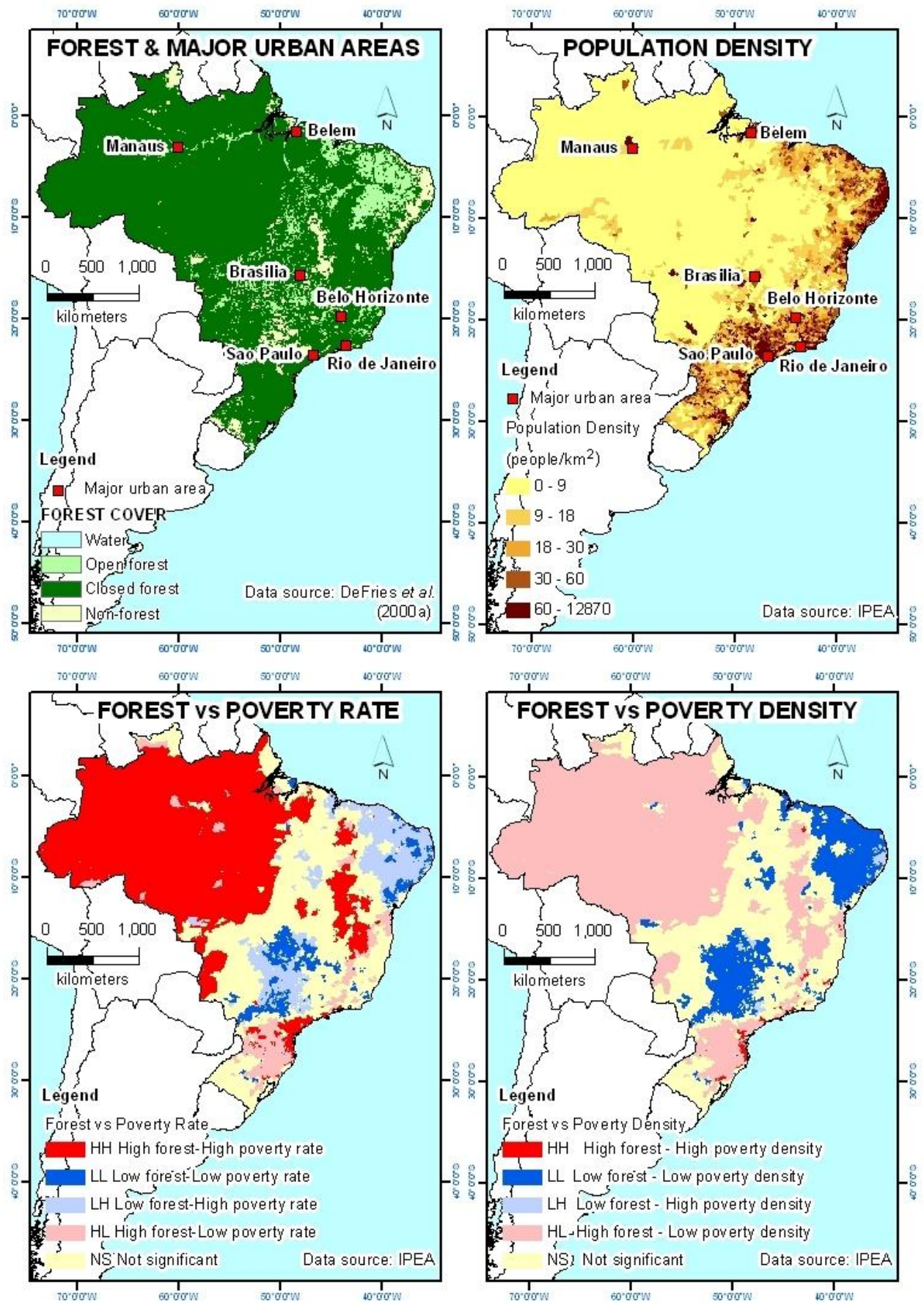
Fig. 2. Honduras. Maps of forest and major urban areas, population density, local indicators of spatial association (LISA) analysis of forest cover by poverty rate, and LISA analysis of forest cover by poverty density.

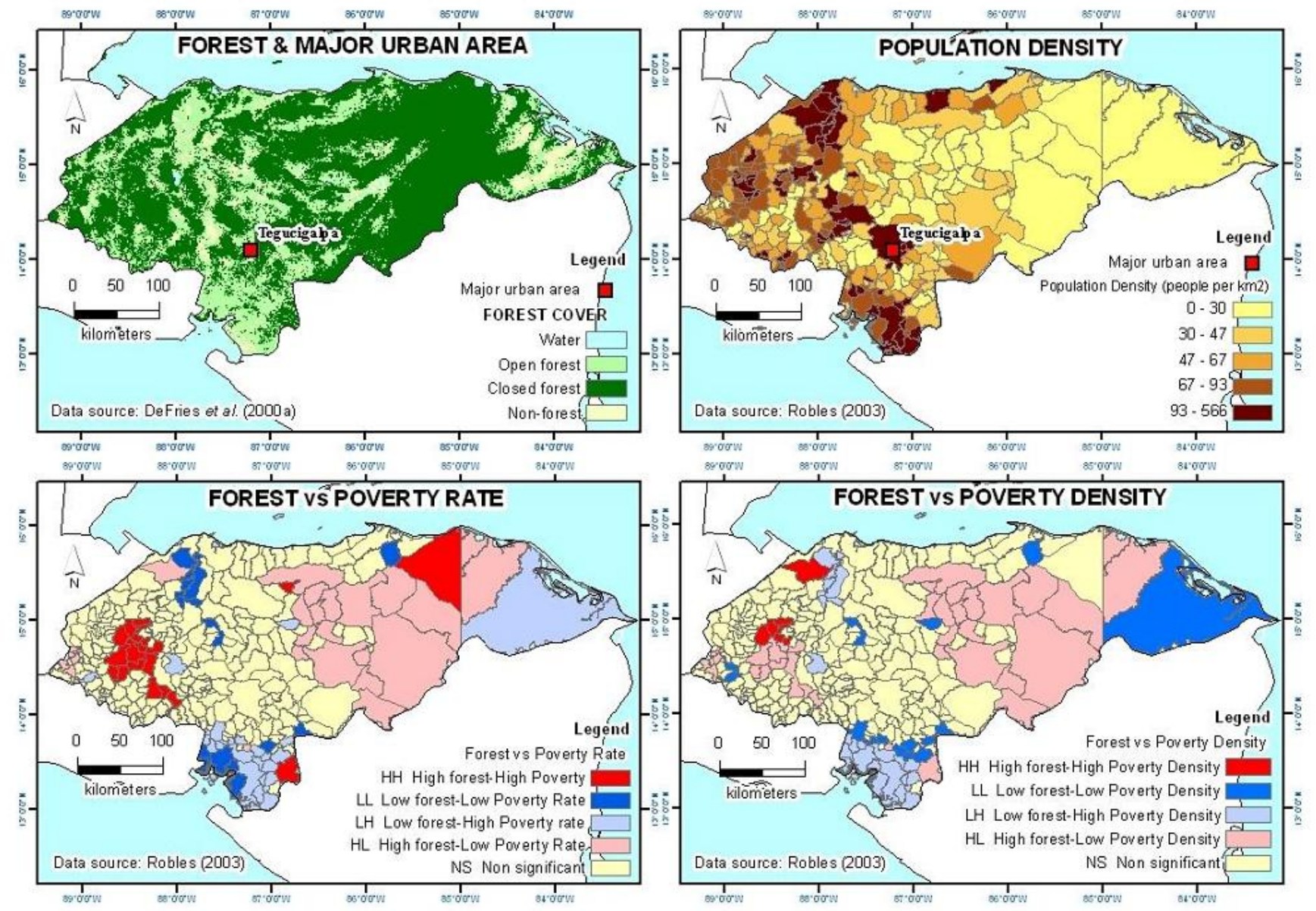

much lower than they are today, and forests were more abundant. In the course of socioeconomic development, the human population has grown exponentially, urban areas have been established, average per capita resource use and income have grown tremendously, and forest cover has receded, especially in and around urban areas and near the network of roads that emanate from cities and other centers of commercial activity. Remote areas have been relatively untouched by the process of modernization, meaning that the people who live in these places (e.g., indigenous people and ethnic minorities) tend to have low per capita consumption, and the forests in which they live tend to be relatively untouched;

2. Higher incomes outside of forests. All things being equal, and with some important exceptions, rural household incomes based on sedentary agriculture tend to be higher than those based on swidden agriculture and/ or forest-based income (e.g., Barbieri et al. 2008). This has to do partly with differences in productivity among these systems and partly with distance to markets. Forests, particularly primary forests, are often located 
Fig. 3. Malawi. Maps of forest and major urban areas, population density, local indicators of spatial association (LISA) analysis of forest cover by poverty rate, and LISA analysis of forest cover by poverty density.

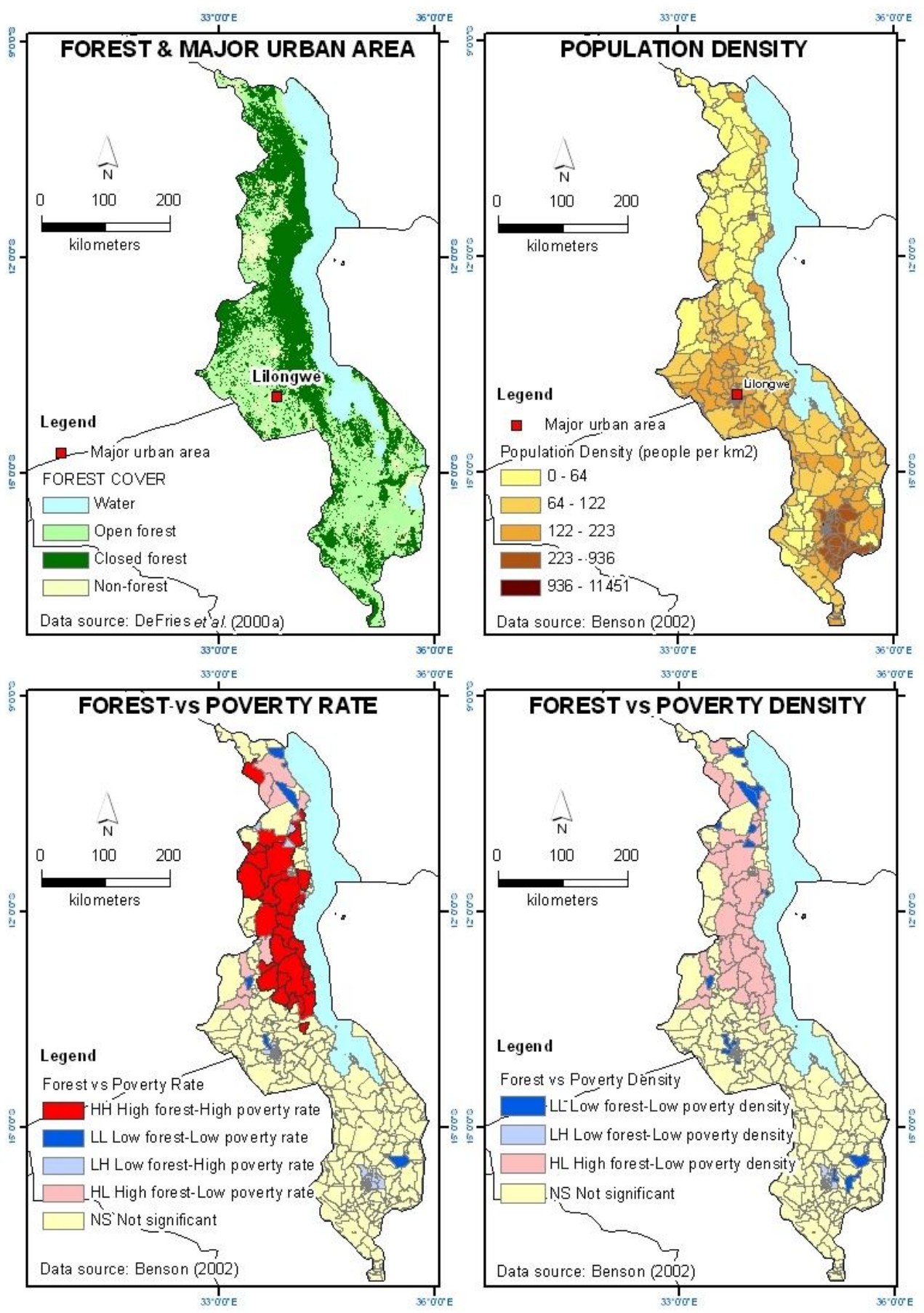


Fig. 4. Mozambique. Maps of forest and major urban areas, population density, local indicators of spatial association (LISA) analysis of forest cover by poverty rate, and LISA analysis of forest cover by poverty density.

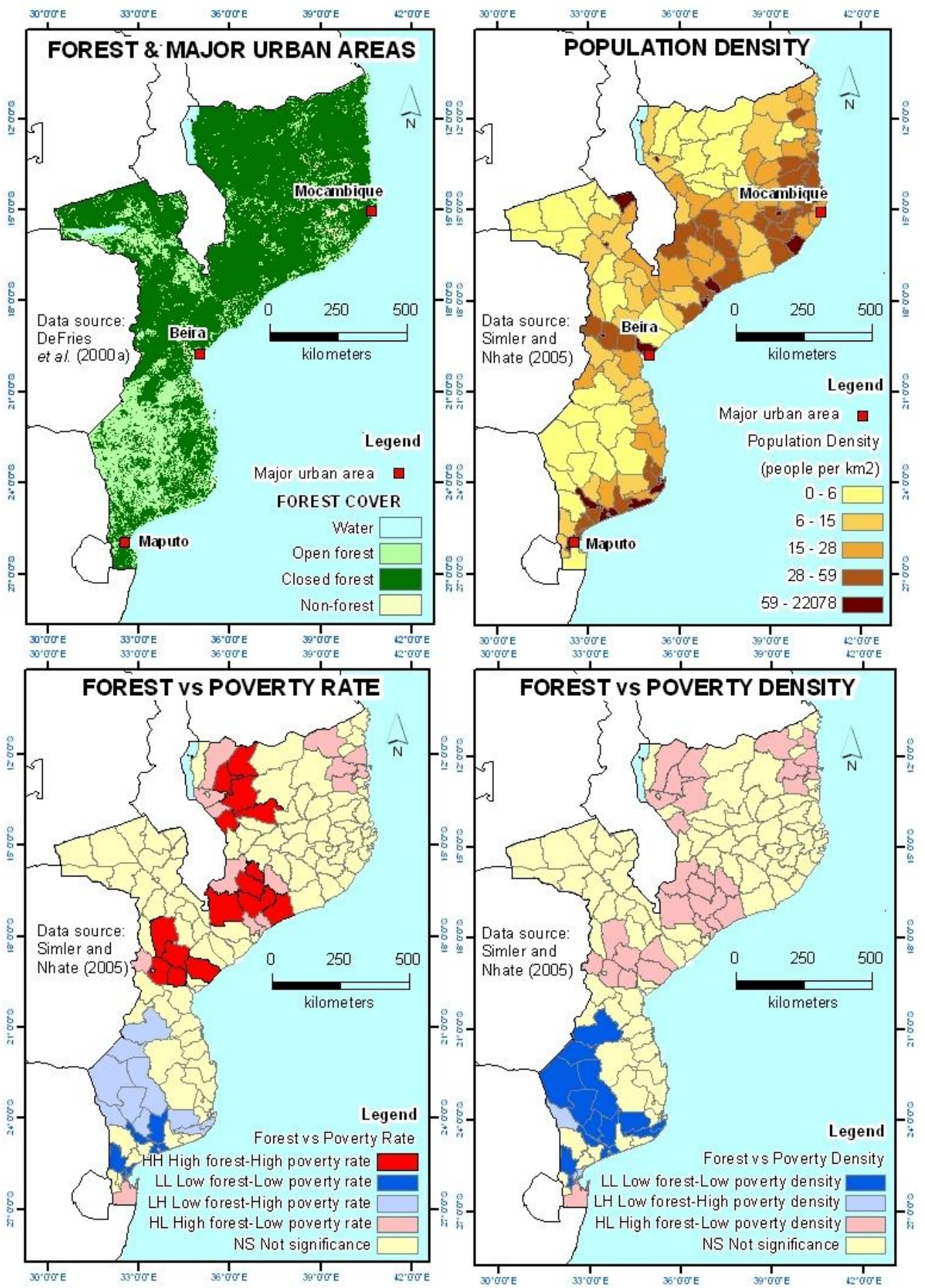


Fig. 5. Uganda. Maps of forest and major urban areas, population density, local indicators of spatial association (LISA) analysis of forest cover by poverty rate, and LISA analysis of forest cover by poverty density.
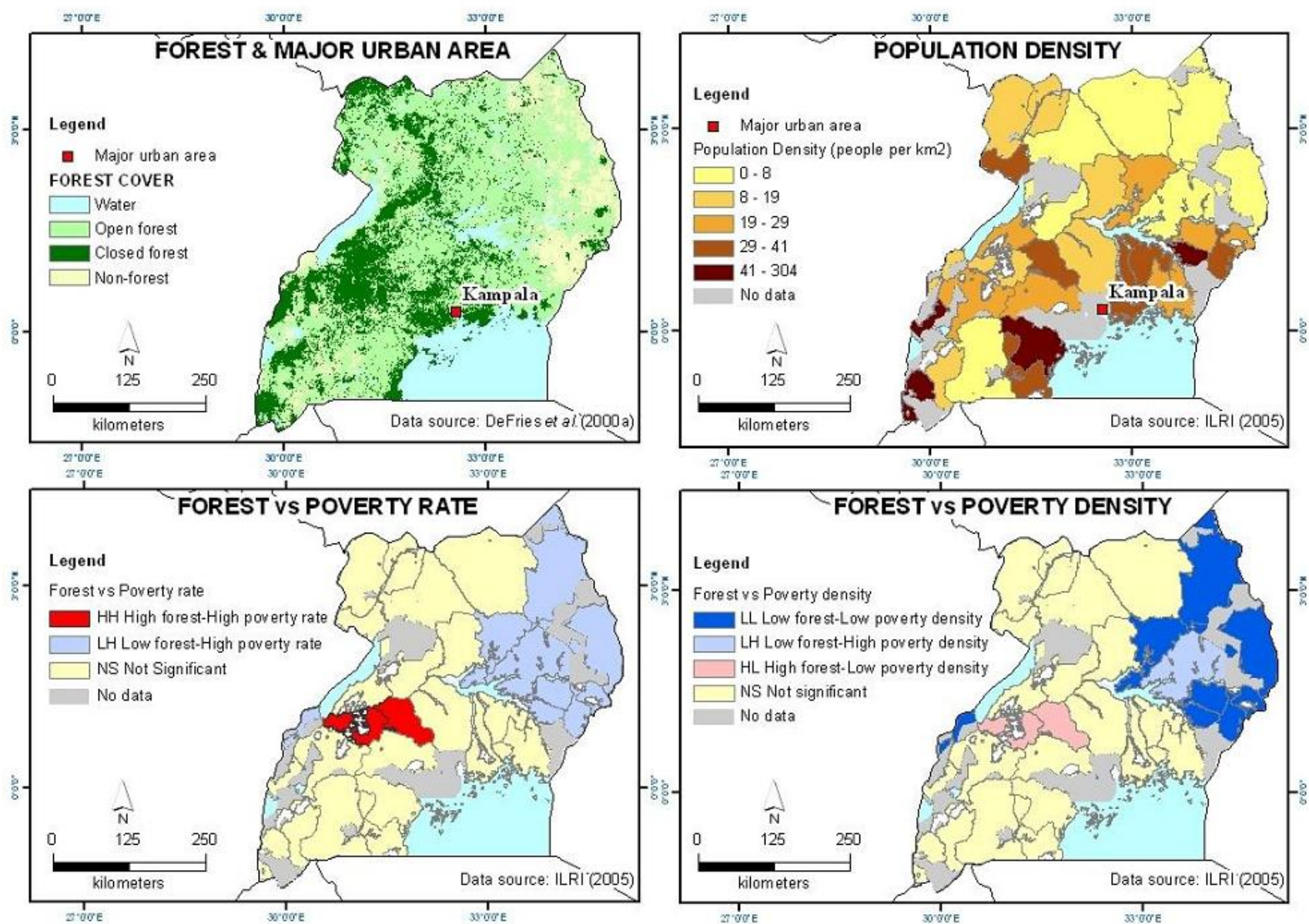

far from markets, which reduces incomeearning opportunities and increases marketing costs. The higher average returns from agriculture is one of the factors that propels the conversion of forest to nonforest uses, as well as some migration out of the forest;

3. Weak tenure in forests. In most developing countries, statutory data show that governments own most of the area of forest land (White and Martin 2002). In contrast, there is a higher rate of private ownership and stronger tenure rights for local people on agricultural lands that are not classified as forests. Strong property rights on agricultural lands tend to translate to more secure livelihoods, investment, and the use of land titles for loan collateral (e.g., Carr 2006). Conversely, weak land and resource tenure tends to mean less secure livelihoods and lower incomes (Food and Agriculture Organization 2002, Deininger 2003, Department for International Development 2007, Swedish International Development Cooperation Agency 2007);

4. Difficulty in capturing forest rents. Although the resource rents are high in forest areas, the means for forest peoples to capture those high 
Fig. 6. Indonesia. Maps of forest and major urban areas, population density, local indicators of spatial association (LISA) analysis of forest cover by poverty rate, and LISA analysis of forest cover by poverty density.
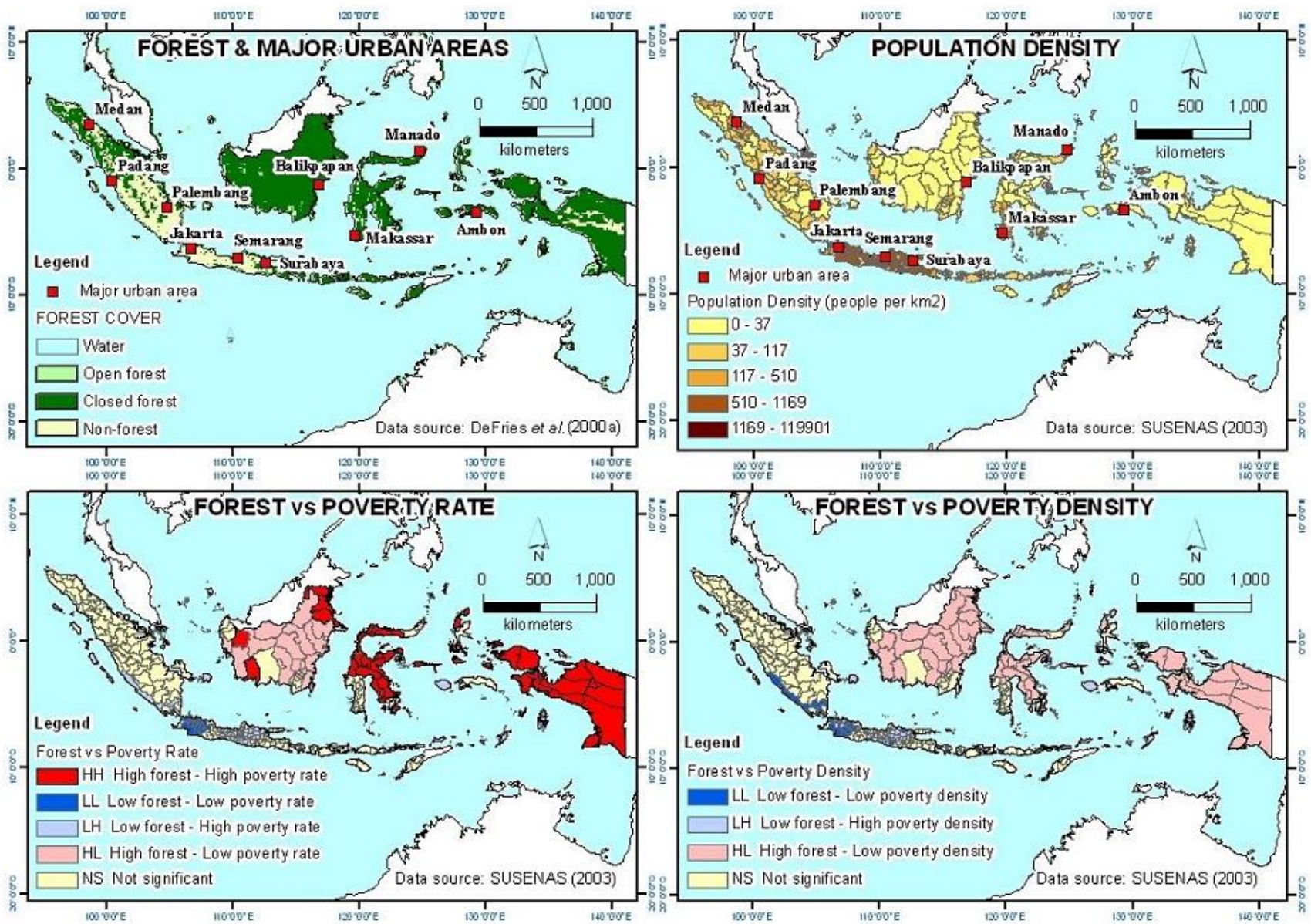

rents, mainly timber, tend to be low because of the high levels of investment, infrastructure, and skill required, and because of legal impediments that prevent them from participating in the stream of benefits;

5. The powerlessness of people in forested areas. The relative powerlessness and low bargaining power of forest dwellers is partly related to their relative isolation from the national polity and economic structure, but it is often imposed. To establish and maintain privileged access to timber and other natural resources, entrepreneurs and the military have used force and intimidation and have established laws and regulations that are designed to constrain local economic options such as land ownership and rights to timber; this has been a strong factor in powerlessness. Powerlessness is further increased by a lack of education and literacy. There are, however, significant exceptions to this pattern;

6. Forests as a magnet for migrants. Forests are often a destination for migration because they tend to be open-access resources outside the reach of state control. Many migrants to forested areas are poor, although they will 
Fig. 7. Vietnam. Maps of forest and major urban areas, population density, local indicators of spatial association (LISA) analysis of forest cover by poverty rate, and LISA analysis of forest cover by poverty density.
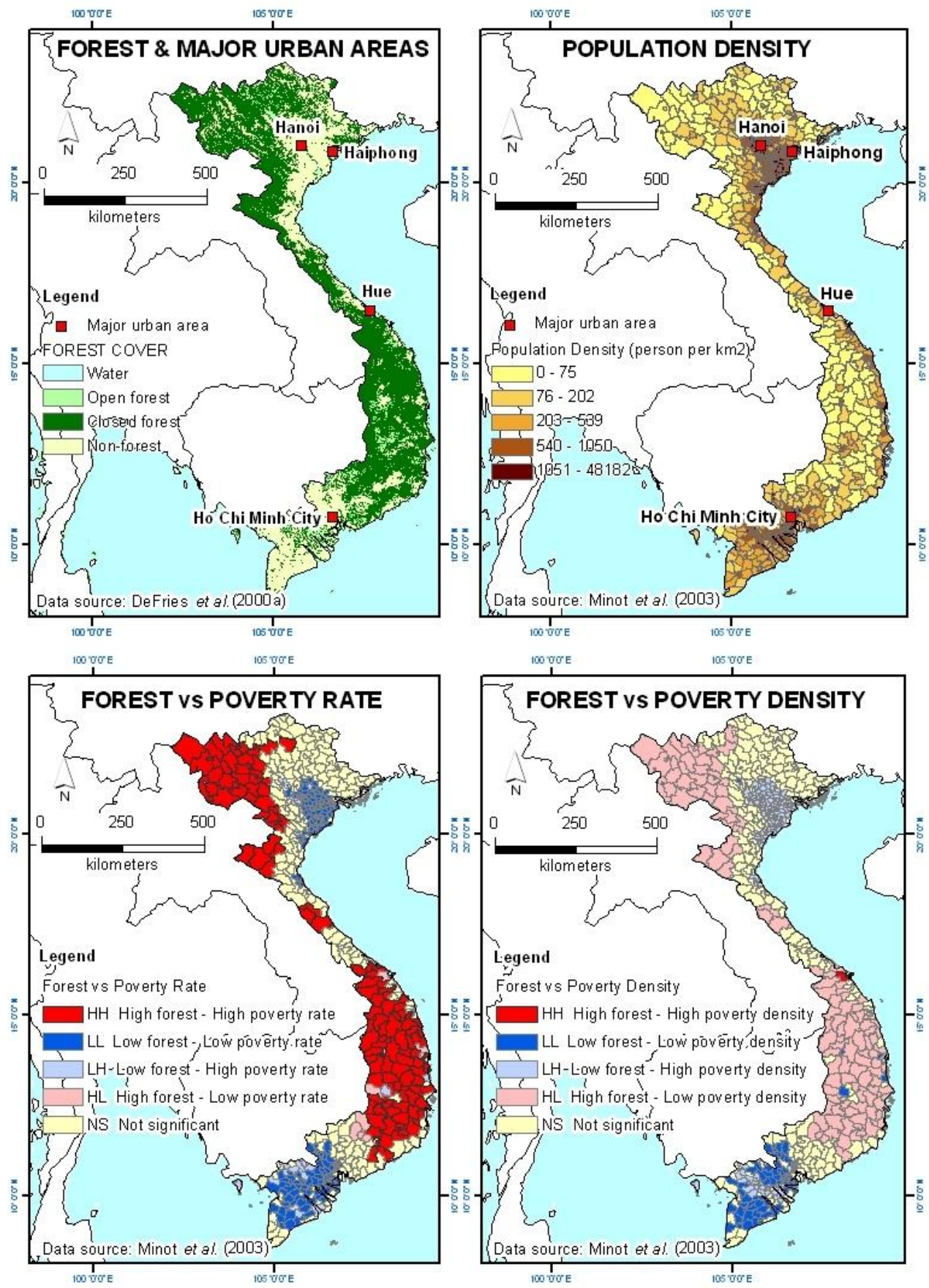
Fig. 8. Distribution of local indicators of spatial association forest vs. poverty rate findings by percentage of closed forest area.

\section{Forest vs Poverty Rate}

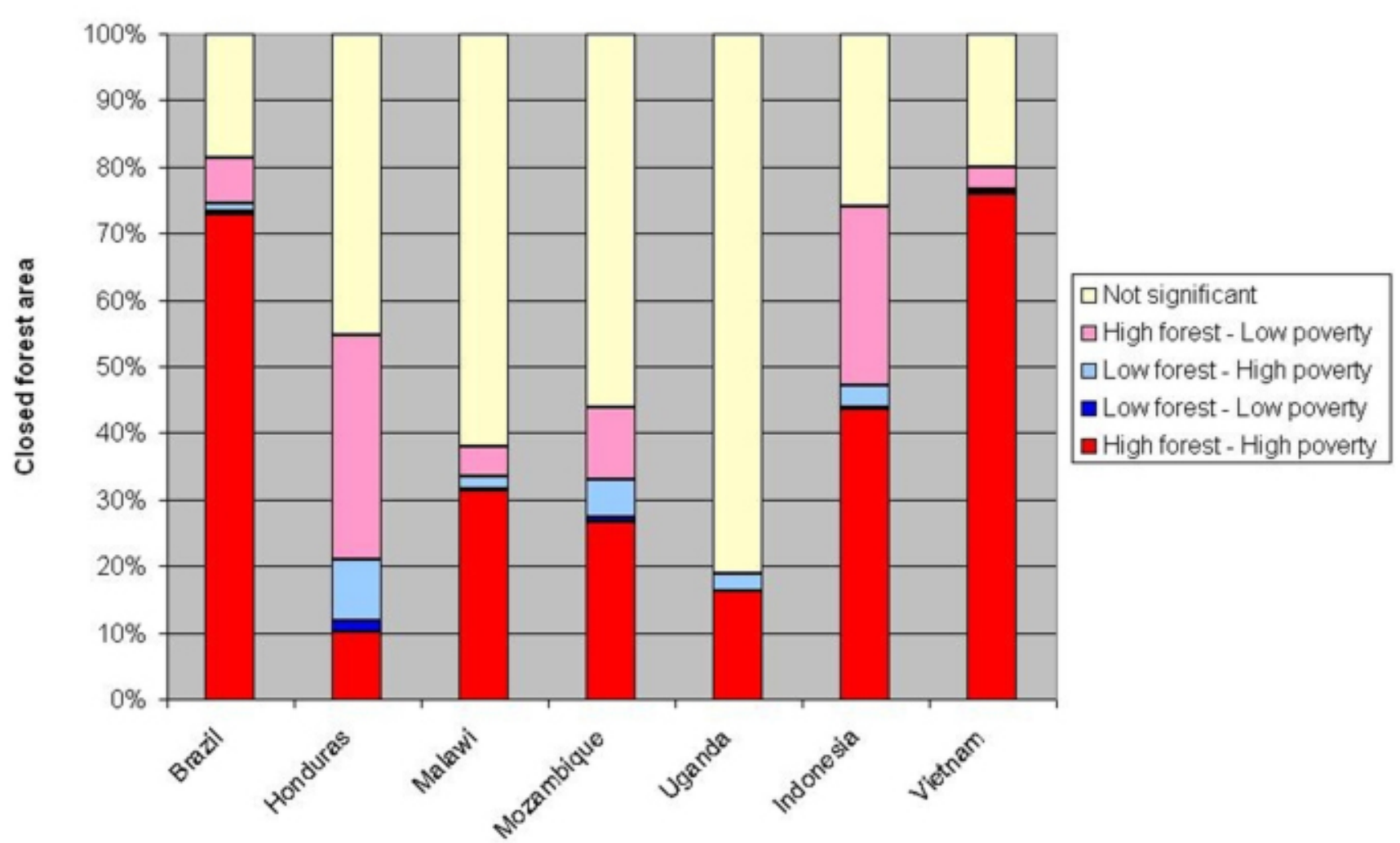

probably not be among the poorest of the poor because it requires savings to undertake migration. Some reasons for migrating to the forest are, however, not economic. Forests have a high presence of poor people in some countries because they have served as a refuge for people fleeing persecution, conflict, and war;

7. Low investment in remote areas. In some developing countries, the rate of government investment in remote rural areas is low (e.g., the lower Amazon: Futemma and Brondízio 2003). One likely explanation is that there are low returns to investment in remote areas. For example, a given amount of investment serves many fewer people in rural areas than in near-urban areas. Another explanation relates to the powerlessness of people in forested areas. Because of their relative powerlessness, forest dwellers often do not have the bargaining power required to get a favorable decision from people in cities who make decisions on public investments. 
Fig. 9. Distribution of local indicators of spatial association forest vs. poverty rate findings by percentage of poor people.

\section{Forest vs Poverty Rate}

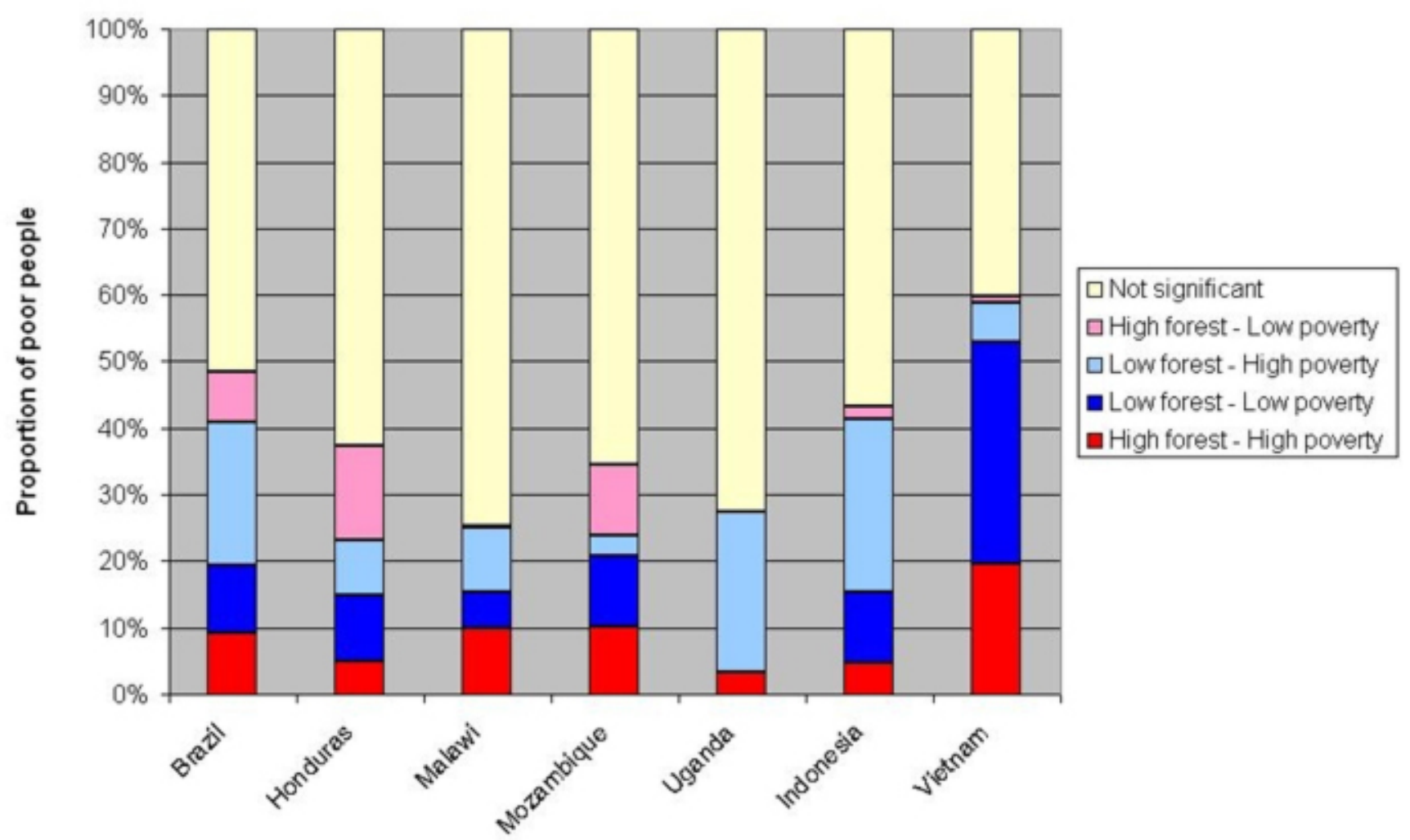

\section{DISCUSSION}

We think that much more attention to forests is deserved in national poverty alleviation strategies for two reasons. First, despite the comparatively low poverty densities that we identified, there are many poor people who live in forest environments. Second, there are nuances of forest poverty that require specific attention to be addressed satisfactorily.

\section{Many poor people live in forest environments}

Superficially, the findings seem to say that national poverty reduction strategies are justified in giving scant attention to forests. After all, on a national scale, a small proportion of the poor tend to live in forests. However, there is one important way in which the local indicators of spatial association results seriously understate the spatial association between the numbers of poor people and nearby forests.

There are places in developing countries where forest cover is low ( $<40 \%$ canopy cover) and yet forest resources can be a significant source of household income in these areas. If anything, forest 
resources can be seen as more important to poverty alleviation in some of these areas than in denser forests because a large number of people live in such forests and forests in these open forest areas are conceivably supplying basic needs for a large number of people. Such places include the savannah and woodlands of the Cerrado in eastern Brazil (Fig. 1), the Miombo Woodlands in various parts of Malawi and Mozambique (Figs. 3 and 4), and some dry forest areas in eastern Indonesia (Fig. 6). Outside of our case study countries, this consideration is important in other Miombo countries, i.e., Angola, Burundi, Democratic Republic of Congo, Tanzania, Zambia, and Zimbabwe.

How many poor people live in all forest environments? As yet there are no reliable estimates. Although the proportion of all poor people living in areas of high forest cover may be low (Fig. 9), the absolute numbers are high in some countries. If only $10 \%$ of all poor in China and India live in areas of high forest cover (not to mention areas of low forest cover), this would amount to > 50 million people.

\section{Nuances of forest poverty that require specific attention}

A high poverty rate is often linked with a high depth and severity of poverty. The Foster, Greer, and Thorbecke (FGT) class of poverty measures (Foster et al. 1984) defines the depth of poverty $(\alpha=1)$ as the average distance of the poor below the poverty line (i.e., the income gap). The severity of poverty $(\alpha=2)$ is the average of the square of the depth of poverty, i.e., giving more weight to the very poorest. Various studies show that the rate, depth, and severity of poverty are often higher in rural than in urban areas (Oduro and Aryee 2003, Shimeles and Thoenen 2005). Likewise, chronic poverty has been observed to be a correlate of high poverty rate, depth, and severity, but this tendency cannot be assumed in all cases and remains an empirical question in need of verification (Hulme 2003, Hulme and Shepherd 2003). Chronic poverty is defined as occurring "...when an individual experiences significant capability deprivations for a period of five years or more" (Hulme and Shepherd 2003:404-405). Chronic poverty tends to be pronounced in remote rural areas and mountainous areas (McKay and Lawson 2003). This may explain the observed correlation between high poverty rate, depth, and severity on the one hand, and chronic poverty on the other. Thus, if there is a national program to eradicate the nodes of poverty that are the most difficult to address, then it may make sense to target areas of high forest cover, among other remote areas, because their inhabitants are likely to exhibit these kinds of poverty.

The high poverty rate characteristic of wide areas of forest in some countries (e.g., Brazil and Vietnam; Fig. 8) can lend itself to some efficiency gains in addressing poverty. Although it is undoubtedly challenging to reduce poverty in remote forested areas, with a high cost of public investment per capita among other problems, there will at least be low rates of leakage (i.e., benefits absorbed by the nonpoor) in such areas.

What kind of poverty alleviation policies should be pursued in relation to forest resources? It is not appropriate to address this question in depth here, both because it is unwise to generalize from our findings to particular countries and because there is already ample literature on this topic. Nevertheless, we put forward some thoughts on this subject.

There is likely a relatively high dependence on forests for livelihoods in areas of high forest cover and high poverty, so it may make sense to promote the use of forest resources as a part of the poverty alleviation strategy in these places. Promising opportunities of this kind occur in places where nonforest livelihood alternatives are few, e.g., migration is difficult or not sought or the agricultural land quality is low, and where the sustainable use of forest resources is possible, among other preconditions.

However, it is important to bear in mind that even lands without forests are potentially important for tree-based poverty alleviation strategies. This is because some areas without forest, especially periurban zones, are often wood deficit areas where the poor can base their livelihoods on supplying the need for timber, firewood, charcoal, and wood crafts through smallholder plantations and small-scale industries. The poor who live in areas of low forest cover and high poverty rate (Fig. 9, light blue) are potential beneficiaries of investments in such strategies.

We mentioned that high rates of poverty in forested areas are in part the product of geographical remoteness. In these places, it is appropriate to 
pursue poverty alleviation strategies that are specifically geared to overcome the disadvantages imposed by remoteness, for example, the construction of roads and bridges, introduction of markets, and facilitation of outmigration if it is sought. Nevertheless, these policies may be insufficient if they do not take into account forest resource dependence and the comparative powerlessness of forest dwellers in remote areas. To assist in overcoming this powerlessness, governments can either do so passively, e.g., by not standing in the way of the grassroots movements for resource control that are underway, or actively, e. g., by working to rescind laws and regulations that have perpetuated disadvantages.

\section{CONCLUSION}

We sought to evaluate the proposition that forests are important to the poor in developing countries not just because of what they offer, but just as importantly, because of where they are located in relation to the places where the poor live. Our findings, based on case studies in Brazil, Honduras, Malawi, Mozambique, Uganda, Indonesia, and Vietnam, indicate that there is a discernible tendency for areas of high forest cover to be characterized by a high poverty rate. However, high forest cover also tends to be associated with low poverty density. This makes sense because most dense forests are not places that can support dense human habitation.

We argue that national poverty alleviation strategies should give greater attention to forest resources than they do currently because there are large numbers of poor who live in forests of all kinds, both closed and open, and because the high poverty rate that is characteristically found in areas of high forest cover is often associated with deep, severe, and chronic poverty. We observe that forest-based poverty alleviation strategies can be relevant regardless of whether there are forests in the landscape. Poverty alleviation strategies that are customarily applied to remote areas should be complemented by support to initiatives that are aimed at overcoming the political powerlessness of people who live in remote forested regions.

Our findings are important because they put past assumptions about the spatial link between poverty and forests on a stronger empirical footing and because they make a strong case for a course correction in some national poverty alleviation strategies. Nevertheless, future research of this kind conducted through additional country case studies would be valuable and can be done when data become available. New studies can reinforce the need to take forestry more seriously in development planning and policies. The maps produced through such research can be a valuable tool for spatial targeting of rural development programs and policies. Moreover, multivariate and time series analyses will allow a more thorough understanding of the causality of the associations found here.

Responses to this article can be read online at: http://www.ecologyandsociety.org/voll3/iss2/art24/responses/

\section{Acknowledgments:}

We thank several people who provided excellent comments on a longer report from which this article was derived: Ken Chomitz, Peter Dewees, David Kaimowitz, Bruce McKenney, Daniel Müller, Jeff Sayer, and Luca Tacconi. Andree Ekadinata and Agus Salim provided valuable help in rechecking the data and revising the maps. We alone are responsible for any errors that may remain in the finished product.

\section{LITERATURE CITED}

Anderson, A. B., P. H. May, and M. J. Balick. 1991. The subsidy from nature: palm forests, peasantry, and development on an Amazon frontier. Columbia University Press, New York, New York, USA.

Angelsen, A., and S. Wunder. 2003. Exploring the forest-poverty link: key concepts, issues and research implications. CIFOR Occasional Paper Number 40. Center for International Forestry Research, Bogor, Indonesia. Available online at: http://www.cifor.cgiar.org/Publications/Papers/.

Anselin, L. 1988. Spatial econometrics: methods and models. Kluwer Academic Publishers, Dordrecht, The Netherlands.

Anselin, L. 1995. Local indicators of spatial association-LISA. Geographical Analysis 27 (2):93-115. 
Anselin, L. 2005. Exploring spatial data with $\mathrm{GeoDa}^{T M}$ : a workbook. Spatial Analysis Laboratory, Department of Geography, University of Illinois at Urbana-Champaign, Urbana, Illinois, USA. Available online at: www.sal.uiuc.edu/stuff/stuff-sum/ pdf/geodaworkbook.pdf.

Badan Pusat Statistik. 2000. SUSENAS (national socioeconomic survey) 2000. Badan Pusat Statistik, Jakarta, Indonesia.

Barbieri, A. F., D. L. Carr, and R. E. Bilsborrow. 2008. Migration within the frontier: the second generation colonization in the Ecuadorian Amazon. Population Research and Policy Review in press.

Benson, T. 2002. Malawi: an atlas of social statistics. National Statistical Office, Government of Malawi, Zomba, Malawi, and International Food Policy Research institute, Washington, D.C, USA. Available online at: http://www.ifpri.org/pubs/cp/m alawiatlas.htm.

Bird, K., D. Hulme, K. Moore, and A. Shepherd. 2002. Chronic poverty and remote rural areas. CPRC Working Paper Number 13. Chronic Poverty Research Centre, University of Birmingham, Birmingham, UK. Available online at: www.chron icpoverty.org/pdfs/13Bird et al.pdf.

Byron, R. N., and J. E. M. Arnold. 1999. What futures for the people of the tropical forests? World Development 27(5):789-805.

Carr, D. L. 2006. A tale of two roads: land tenure, poverty, and politics on the Guatemalan frontier. Geoforum 37(1):94-103.

Chambers, R., M. Leach, and C. Conroy. 1993. Trees as savings and security for the rural poor. Gatekeeper Series Number 3. International Institute for Environment and Development, London, UK. Available online at: http://www.iied.org/pubs/pdfs/ 6025IIED.pdf.

Chomitz, K. M. 2007. At loggerheads: agricultural expansion, poverty reduction, and environment in the tropical forests. World Bank, Washington, D. C., USA.

Dasgupta, S., U. Deichmann, C. Meisner, and D. Wheeler. 2005. Where is the poverty-environment nexus? Evidence from Cambodia, Lao PDR, and Vietnam. World Development 33(4):617-638.
DeFries, R., M. Hansen, J. R. G. Townshend, A. C. Janetos, and T. R. Loveland. 2000a. 1 kilometer tree cover continuous fields. Version 1.0. Department of Geography, University of Maryland, College Park, Maryland, USA. Available online at: http://www.landcover.org/data/treecover/.

DeFries, R., M. Hansen, J. R. G. Townshend, A. C. Janetos, and T. R. Loveland. 2000b. A new global $1-\mathrm{km}$ dataset of percent tree cover derived from remote sensing. Global Change Biology 6 (2):247-254.

Deininger, K. 2003. Land policies for growth and poverty reduction. World Bank, Washington, D.C., USA.

Department for International Development. 2007. Land: better access and secure rights for poor people. Department for International Development, London, UK. Available online at: http://www.dfid. gov.uk/pubs/files/LandPaper2007.pdf.

Dercon, S. 2008. Rural poverty: old challenges in new contexts. GPRG-WPS 072. Global Poverty Research Group, Economic and Social Research Council, Oxford, UK. Available online at: www.gp rg.org/pubs/workingpapers/pdfs/gprg-wps-072.pdf

Ellis, F. 2000. Rural livelihoods and diversity in developing countries. Oxford University Press, Oxford, UK.

Food and Agriculture Organization. 2001. Global forest resources assessment 2000: main report. FAO Forestry Paper 140. Food and Agriculture Organization, Rome, Italy. Available online at: htt p://www.fao.org/forestry/fra2000report/en/.

Food and Agriculture Organization. 2002. Land tenure and rural development. FAO Land Tenure Studies 3. Food and Agriculture Organization, Rome, Italy. Available online at: http://www.fao.org/ DOCREP/005/Y4307E/y4307e00.htm.

Foster, J., J. Greer, and E. Thorbecke. 1984. A class of decomposable poverty measures. Econometrica 52(3):761-766.

Futemma, C., and E. S. Brondízio. 2003. Land reform and land-use changes in the lower Amazon: implications for agricultural intensification. Human Ecology 31(3):369-402. 
Hulme, D. 2003. Chronic poverty and development policy: an introduction. World Development 31 (3):399-402.

Hulme, D., and A. Shepherd. 2003. Conceptualizing chronic poverty. World Development 31(3):403-423.

International Livestock Research Institute. 2005. Poverty targeting tool: strategic analysis and knowledge support system (SAKSS). CD-ROM, BETA version. International Livestock Research Institute, Nairobi, Kenya.

Ravallion, M., and J. Jalan. 1997. Spatial poverty traps? World Bank Policy Research Working Paper Number 1862. World Bank, Washington, D.C., USA.

Kanbur, R., and A. J. Venables. 2005. Spatial inequality and development. Pages 3-14 in R. Kanbur and A. J. Venables, editors. Spatial inequality and development. Oxford University Press, Oxford, UK.

Khare, A., M. Sarin, N. C. Saxena, S. Palit, S. Bathla, F. Vania, and M. Satyanarayana. 2000. Joint forest management: policy, practice, and prospects. Policy that Works for Forest and People Series Number 3. World Wide Fund for Nature, New Delhi, India, and International Institute for Environment and Development, London, UK.

McKay, A., and D. Lawson. 2003. Assessing the extent and nature of chronic poverty in low income countries: issues and evidence. World Development 31(3):425-439.

McSweeney, K. 2004. Forest product sale as natural insurance: the effects of household characteristics and the nature of shock in eastern Honduras. Society and Natural Resources 17(1):39-56.

Mehta, A. K., and A. Shah. 2003. Chronic poverty in India: incidence, causes and policies. World Development 31(3):491-511.

Minot, N., B. Baulch, and M. Epprecht. 2003. Poverty and inequality in Vietnam: spatial patterns and geographic determinants. International Food Policy Research Institute, Washington, D.C., USA, and Institute of Development Studies, Brighton, UK. Available online at: http://www.ifpri.org/divs/ MTID/DR/dr200312mapping.htm.
Müller, D., M. Epprecht, and W. D. Sunderlin. 2006. Where are the poor and where are the trees? Targeting of poverty reduction and forest conservation in Vietnam. CIFOR Working Paper Number 34. Center for International Forestry Research, Bogor, Indonesia. Available online at: http://www.cifor.cgiar.org/Publications/Papers/wkpapers/

Oduro, A. D., and I. Aryee. 2003. Investigating chronic poverty in West Africa. Chronic Poverty Research Centre Working Paper Number 28. Centre for Policy Analysis, University of Manchester, Manchester, UK. Available online at: http://www.c hronicpoverty.org/pdfs/280duro Aryee.pdf.

Oksanen, T., and C. Mersmann. 2003. Forests in poverty reduction strategies: an assessment of PRSP process in sub-Saharan Africa. Pages 121-155 in T. Oksanen, B. Pajari, and T. Tuomasjukka, editors. Forests in poverty reduction strategies: capturing the potential. EFI Proceedings Number 47. European Forest Institute, Joensuu, Finland. Available online at: http://www.efi.int/portal/virtua 1 library/publications/proceedings/47/.

Pattanayak, S. K., and E. O. Sills. 2001. Do tropical forests provide natural insurance? The microeconomics of non-timber forest product collection in the Brazilian Amazon. Land Economics 77(4):595-612.

Robles, M. 2003. Estimación de indicadores de pobreza y desigualdad a nivel municipal en Honduras. BID/MECOVI-Instituto Nacional de Estadística, Tegucigalpa, Honduras.

Ruíz Pérez, M., B. Belcher, M. Fu, and X. Yang. 2004. Looking through the bamboo curtain: an analysis of the changing role of forest and farm income in rural livelihoods in China. International Forestry Review 6(3-4):306-316.

Shah, A., and B. Guru. 2004. Poverty in remote rural areas in India: a review of evidence and issues. CPRC-IIPA Working Paper Number 21. Indian Institute of Public Administration, New Delhi, India. Available online at: http://www.chronicpoverty. org/p/308/publication-details.php.

Shimeles, A., and R. Thoenen. 2005. Poverty profiles: a methodological note on measuring poverty. Working Paper ESPD/NRP/04/05. United Nations Economic Commission for Africa, Addis 
Ababa, Ethiopia. Available online at: www.uneca.o rg/espd/publications/Poverty profiles a methodol ogical note on measuring pove.pdf.

Simler, K. R., and V. Nhate. 2005. Poverty, inequality, and geographic targeting : evidence from small-area estimates in Mozambique. FCND Discussion Paper Number 192. International Food Policy Research Institute, Washington, D.C., USA. Available online at: http://ideas.repec.org/p/fpr/fcn ddp/192.html.

Sunderlin, W. D., A. Angelsen, B. Belcher, P. Burgers, R. Nasi, L. Santoso, and S. Wunder. 2005. Livelihoods, forests, and conservation in developing countries: an overview. World Development 33(9):1383-1402.

Sunderlin, W. D., S. Dewi, and A. Puntodewo. 2007. Poverty and forests: multi-country analysis of spatial association and proposed policy solutions. CIFOR Occasional Paper Number 47. Center for International Forestry Research, Bogor, Indonesia. Available online at: http://www.cifor.cgiar.org/Pub lications/Papers/.

Swedish International Development Cooperation Agency. 2007. Natural resource tenure: a position paper for SIDA. Swedish International Development Cooperation Agency, Stockholm, Sweden. Available online at: http://www.sida.se/sida/jsp/sida.jsp?d=11 $\underline{8 \& a}=32805 \&$ language $=$ en US.

Takasaki, Y., B. L. Barham, and O. T. Coomes. 2004. Risk coping strategies in tropical forests: floods, illnesses and resource extraction. Environment and Development Economics 9(2):203-224.

Vedeld, P., A. Angelsen, E. Sjaastad, and G. Kobugabe Berg. 2004. Counting on the environment: forest incomes and the rural poor. Environmental Economics Series Number 98. World Bank, Washington, D.C., USA. Available online at: http://lnweb18.worldbank.org/essd/envext. nsf/44ByDocName/CountingontheEnvironmentFor estIncomesandthe RuralPoor2004/\$FILE/

CountingontheEnvironmentForestIncomesandtheR uralPoor.pdf.

White, A., and A. Martin. 2002. Who owns the world's forests? Forest tenure and public forests in transition. Forest Trends and Center for International Environmental Law, Washington, D. C., USA. Available online at: www.forest-trends.org/ documents/publications/tenurereport whoowns.pdf
World Bank. 2006. India: unlocking opportunities for forest-dependent people in India. Report Number 34481-IN. World Bank, Washington, D.C., USA. Available online at: http://siteresources.worl dbank.org/INDIAEXTN/Resources/ReportsPublications/366387-1143196617295/ Forestry Report volume I.pdf.

Zhou, L., and G. Veeck. 1999. Forest resource use and rural poverty in China. Forestry Economics 4 (1):80-92. 